\title{
A RARE CASE REPORT OF DEEP VEIN THROMBOSIS IN PREGNANCY WITH BLIGHTED OVUM
}

\author{
G. Sudha Rani1, Manish Pendse'2, V. R. Badhwar ${ }^{3}$
}

${ }^{1}$ Associate Professor, Department of Obstetrics \& Gynaecology, D. Y. Patil School of Medicine, Navi Mumbai.

${ }^{2}$ Associate Professor, Department of Medicine, D. Y. Patil School of Medicine, Navi Mumbai.

3 Professor, Department of Obstetrics \& Gynaecology, D. Y. Patil School of Medicine, Navi Mumbai.

\begin{abstract}
The risk of Venous thrombosis in otherwise healthy women is considered to be highest during pregnancy and puerperium. ${ }^{1}$ It usually presents as pain in the calf or thigh and swelling of the leg, most commonly in left leg. During pregnancy the risk of thrombosis is higher in women with associated genetic risk factors. The case being presented here is a rare case of deep vein thrombosis in pregnancy with blighted ovum.
\end{abstract}

\section{KEYWORDS}

Deep Vein Thrombosis, Venous Thromboembolism, Thrombophilia.

HOW TO CITE THIS ARTICLE: G. Sudha Rani, Manish Pendse, V. R. Badhwar. "A Rare Case Report of Deep Vein Thrombosis in Pregnancy with Blighted Ovum." Journal of Evolution of Medical and Dental Sciences 2015; Vol. 4, Issue 100, December 14; Page: 16591-16592, DOI: 10.14260/jemds/2015/2472

\section{INTRODUCTION}

The risk of venous thrombosis is five-fold higher in pregnant women when compared to other women of similar age. Incidence of all thromboembolic events averages about 1 per 1000 pregnancies.[1] Most cases of venous thrombosis during pregnancy occur in the deep veins of the lower extremity. A $90 \%$ of these were in the left leg. The risk factors associated with the development of thromboembolism during pregnancy are:

a) Age 35 yrs. or more.

b) History of thrombosis.

c) Having thrombophilia.

d) Obesity (BMI $30 \mathrm{~kg} / \mathrm{m}^{2}$ or more).

e) Having fertility treatment.

f) Oral contraceptive use.

As pregnancy itself is a hypercoagulable state the risk of venous thromboembolism increases in pregnancy. This is a very rare case of deep vein thrombosis (DVT) in a 34-year-old female Gravida 2 para 1 live 1 with 6 weeks of amenorrhoea with blighted ovum.

\section{CASE REPORT}

A 34-year-old female $\mathrm{G}_{2} \mathrm{P}_{1} \mathrm{~L}_{1}$ with 6 weeks of amenorrhoea presented with complaint of pain in the back on left side and left thigh, which was followed by swelling of left lower limb which progressed from thigh to the foot gradually in 10 days. There is no history of trauma, fall or fever. Her menstrual cycles are regular. She had one full term normal vaginal delivery 4 years back which was uneventful. There was no history of contraceptive usage. There was no previous history and family history of thrombosis or thrombophilia. On general examination she was stable. Her vital data were within normal limits. No abnormality was detected on cardiovascular and respiratory examination. On local examination there was generalized pitting edema of left lower limb from thigh to foot. A local rise of skin temperature over the left lower limb was noticed. Definite tenderness of the calf muscles was present.

Financial or Other, Competing Interest: None.

Submission 18-11-2015, Peer Review 19-11-2015

Acceptance 05-12-2015, Published 14-12-2015.

Corresponding Author:

Dr. G. Sudha Rani,

T-801, Army Welfare Society, Sector-9,

Nerul-400706, Navi Mumbai.

E-mail: sudharani_gandi@yahoo.com

DOI:10.14260/jemds/2015/2472
Peripheral pulses were palpable. On per vaginal examination uterus was 6 weeks' size anteverted, os closed, mobile, fornices free and no vaginal bleeding was seen. On investigating, left lower limb venous Doppler showed visualised portion of left external iliac, common iliac, superficial-deep femorals and popliteal veins were noncompressible and showed echogenic material within suggestive of thrombus and extensive subcutaneous edema in the leg and foot. Her haemoglobin was $10 \mathrm{~g} / \mathrm{dl}$, Platelet count 1.59 lakhs $/ \mu \mathrm{l}, \quad$ FDP $450 \mathrm{ng} / \mathrm{ml}$, D-Dimer $4640 \mathrm{ng} / \mathrm{ml}$, fibrinogen $265 \mathrm{mg} / \mathrm{dl}$, PT 16 seconds, APTT 32.4 seconds. APLA IgM, IgG-negative, Antinuclear antibody negative. Rest of the routine blood and urine tests were normal. On ultrasonography single irregular intrauterine gestational sac of 6.2 weeks with minimal subchorionic collection suggestive of blighted ovum seen. B-hcg level on the day of admission was $58901.1 \mathrm{mIu} / \mathrm{ml}$ and it decreased to $29176 \mathrm{mIu} / \mathrm{ml}$ by $5^{\text {th }}$ day of admission confirming embryonal demise.

After the diagnosis of deep vein thrombosis she was started on low molecular weight heparin 0.6 units subcutaneous twice daily for 2 weeks, Tab Ecosprin $75 \mathrm{mg}$ and antibiotics. Due to her condition of DVT and the risk of embolization, routine management of blighted ovum by dilatation and evacuation was withheld. Patient was discharged after 10 days on Tab. Warfarin $1 \mathrm{gm}$. After 2 weeks of discharge patient aborted spontaneously by nature without any complication of excessive bleeding and repeat ultrasonography of pelvis confirmed complete abortion. Patient is following up for last four months, on anticoagulants with subsidence of symptoms of deep vein thrombosis. She had normal periods for last 3 months.

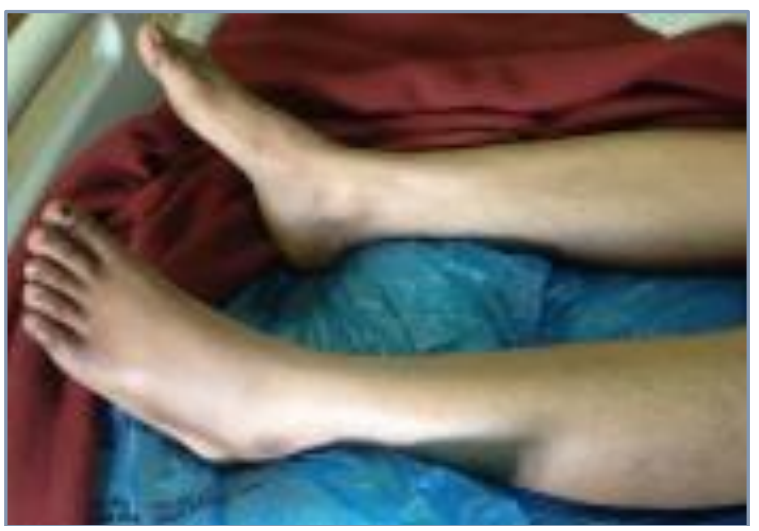

Fig. 1: Deep Vein Thrombosis in Left Leg 


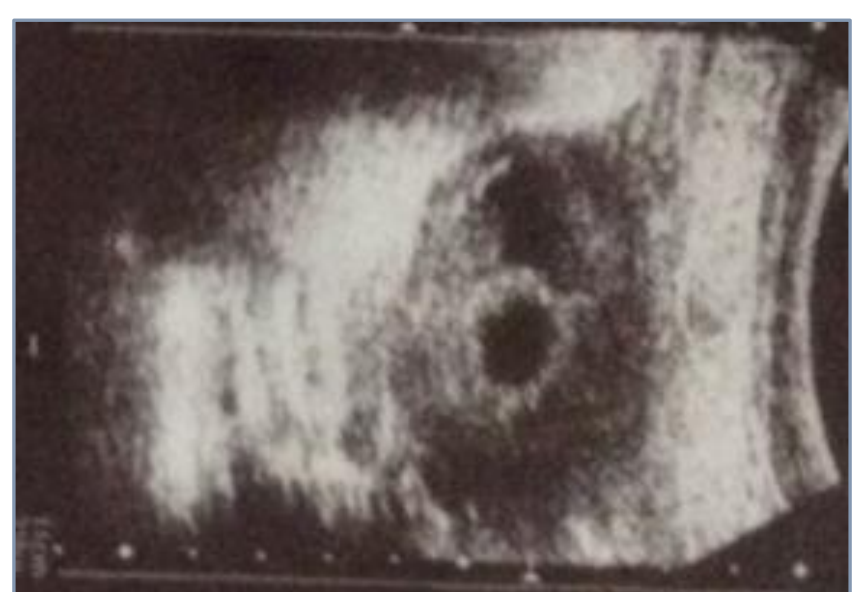

Fig. 2: Ultrasonography of

Pelvis showing Blighted Ovum

\section{DISCUSSION}

Deep vein thrombosis in pregnancy though most commonly seen in postpartum period may also be seen during pregnancy. Stasis, local trauma to the vessel wall and hypercoagulability are the conditions that predispose to the development of venous thrombosis as postulated by Rudolf Virchow. The risk of each of these increases during pregnancy. Hypercoagulability state during pregnancy is due to increase in the synthesis of clotting factors (Factor I, II, VII, IX and X) decreased fibrinolysis and reduced levels of the natural anticoagulant, protein C. In women with associated genetic risk factors the risk of thrombosis increases during pregnancy. Until one of the other risk factors is present, about $50 \%-60 \%$ of patients with a hereditary basis for thrombosis or thrombophilia do not experience of thrombotic event. In a study by James $\mathrm{AH}$ et al.[2] it was reported that $44 \%$ of patients experienced DVT in first trimester of pregnancy indicating that the risk starts early in pregnancy. In another study by Blanco-Molina et al.[3] it was reported that thrombophilia tests were more often positive in women who developed venous thromboembolism during the first trimester of pregnancy.

Amita Suneja et al.[4] reported in the article that as thrombophilia is rarely seen in Asian and African women, diagnostic workup for thrombophilia is not indicated in all cases of DVT in pregnancy, but selected patients with clinical indicators of hypercoagulable state like family history of thrombosis, recurrent thrombosis, idiopathic thrombosis, thrombosis at unusual sites (i.e., Axilla, Cerebral, Mesentric, Portal, Hepatic Veins) needs to be evaluated for thrombophilia. In spite of extensive search for references we were unable to find any references for DVT in pregnancy with blighted ovum. As in our case DVT occurred at 6 weeks of pregnancy with blighted ovum, it is too early for the pregnancy related conditions for thrombosis to be the cause and so it comes into the category of idiopathic thrombosis. Hence, this patient needs to be further investigated for the presence of thrombophilia.

\section{REFERENCES}

1. F Gary Cunningham, Kenneth J Leveno, Steven L Bloom, John C Hauth, Larry C Gilstrap, Katharine D Wenstrom. Williams Obstetrics 22nd edition 2005; 1074-1088.

2. James AH1, Tapson VF, Goldhaber SZ. Thrombosis during pregnancy and the postpartum period. Am J Obstet Gynecol 2005 Jul;193(1):216-9.

3. Blanco-Molina A1, Trujillo-Santos J, Criado J, Lopez L, Lecumberri R, Gutierrez R, et al.; RIETE Investigators. Venous thromboembolism during pregnancy or postpartum: findings from the RIETE Registry. Thromb Haemost 2007; Feb: 97(2):186-90.

4. Amita Suneja, Rashmi, Manjeet Arora, et al. Deep Vein Thrombosis (DVT) in Pregnancy. Journal, Indian Academy of Clinical Medicine - Vol. 2, No. 4 OctoberDecember 2001; 260-269. 